\title{
Retrospective analysis of factors associated with quetiapine dosage in the acute and subsequent six-month maintenance treatment of bipolar disorders
}

\author{
This article was published in the following Dove Press journal: \\ Neuropsychiatric Disease and Treatment \\ 25 April 2013 \\ Number of times this article has been viewed
}

\section{Ling Zhang \\ Gang Wang \\ Jiong Luo \\ Qing-E Zhang \\ Qian Zhao \\ Qi-Ying Deng \\ $\mathrm{Xin} \mathrm{Ma}$}

Mood Disorders Center, Beijing Anding Hospital, Capital Medical University, Beijing, People's

Republic of China
Correspondence: Xin Ma

Beijing Anding Hospital, CMU,

5 Ankang Hutong, Xicheng District,

Beijing I00088, People's

Republic of China

$\mathrm{Tel}+861058303186$

Fax +86 I0 82089804

Email maxinandingyiyuan@gmail.com
Background: Although quetiapine has often been used as monotherapy or adjunctive therapy in bipolar disorder, there is very limited clinical evidence regarding prescribing practices for quetiapine as maintenance treatment for bipolar disorder.

Methods: We reviewed the inpatient and outpatient records of 175 Chinese patients who received treatment with quetiapine for bipolar disorder both during and following hospitalization. We compared patients treated with high-dose ( $>300 \mathrm{mg} /$ day $)$ and low-dose ( $\leq 300 \mathrm{mg} /$ day $)$ quetiapine during the acute treatment phase and in the subsequent 6 months of maintenance treatment, with assessments at months 1, 3, and 6. Multifactor logistic regression analysis was performed to identify factors associated with quetiapine dosage.

Results: The proportion of patients receiving combination therapy of quetiapine and a mood stabilizer as acute and maintenance treatment was $99.4 \%$ and $84.6 \%$, respectively. The mean dose of quetiapine when used for acute treatment in the 175 patients was $395.7 \mathrm{mg} / \mathrm{day}$. The following factors were found to be independently associated with use of high-dose quetiapine: male gender (odds ratio [OR] 2.712, 95\% confidence interval [CI] 1.372-5.362, $P<0.01$ ), a manic or mixed episode (OR 2.786, 95\% CI 1.362-5.699, $P<0.01$ ), and psychotic features (OR 2.658, 95\% CI $1.318-5.361, P<0.01)$. In the subsequent 6 months, the mean dose of quetiapine prescribed steadily decreased to $375.0 \mathrm{mg} /$ day, $330.6 \mathrm{mg} /$ day, and $293.7 \mathrm{mg}$ /day at months 1,3 , and 6 . The main factors associated with high-dose quetiapine in maintenance treatment were male gender (month 1, OR 2.761; month 3, OR 2.583; month 6, OR 2.686; $P<0.01$ ) and a manic or mixed episode (month 1, OR 2.626; month 3, OR 2.334; $P<0.01$ ).

Conclusion: Higher doses of quetiapine ( $>300 \mathrm{mg} /$ day) are more likely to be prescribed to patients who are male, those who are experiencing a manic or mixed episode, and those who have psychotic features during acute treatment of bipolar disorder. For patients who remain clinically stable during the subsequent months, the quetiapine dose should be adjusted according to patient gender and the most recent type of episode experienced.

Keywords: quetiapine, bipolar disorder, acute treatment, maintenance treatment, dosage

\section{Introduction}

Several previous studies have shown that quetiapine can be used as monotherapy ${ }^{1-3}$ or in combination therapy with a classical mood stabilizer to treat bipolar mania ${ }^{4}$ and bipolar depression. ${ }^{5}$ Further, quetiapine has been shown to be effective in the prevention of relapses in bipolar disorder. ${ }^{6-8}$ The practice guideline for the treatment of patients with bipolar disorder published by the American Psychiatric Association in 2002 indicates that "... following remission of an acute episode, patients may remain at particularly 
high risk of relapse for a period of up to 6 months; this phase of treatment, sometimes referred to as continuation treatment, is considered in this guideline to be part of the maintenance phase. For patients treated with an antipsychotic medication during the preceding acute episode, the need for ongoing antipsychotic treatment should be reassessed upon entering maintenance treatment." However, there is limited clinical evidence regarding prescribing patterns for quetiapine when used as maintenance treatment for bipolar disorder. This retrospective study attempted to identify factors which could affect prescribing decisions regarding quetiapine in this indication.

\section{Materials and methods Study design}

The data were collected from 175 patients who were admitted to Beijing Anding Hospital (Capital Medical University, Beijing, People's Republic of China) and received treatment for bipolar disorder between January 2009 and October 2010. Two senior psychiatric clinicians reviewed the inpatient and outpatient medical records of these patients to identify factors associated with the quetiapine dose prescribed during the acute hospitalization phase and later during the posthospitalization maintenance phase in patients who were clinically stable, with assessments at months 1,3 , and 6 .

A research questionnaire designed specifically for this study was used to collect data from medical records, including demographic information, history of mental illness, family history, the most recent episode type (mania, depression, or mixed), presence or absence of psychotic features, the quetiapine dose prescribed during acute and maintenance treatment, reasons for any adjustment of the quetiapine dose, and subsequent patient stability.

The inclusion criteria were: Chinese ethnicity; age 16-65 years; fulfillment of the diagnostic criteria for bipolar disorder according to the International Statistical Classification of Diseases and Related Health Problems 10th Revision (ICD-10); having received systemic treatment during hospitalization, including quetiapine as an antipsychotic medication, with or without concomitant mood stabilizers or antidepressants; significant improvement in symptoms at hospital discharge; compliance with medication; stable clinical status during the 6 months post discharge; and residing in Beijing, to ensure at least one follow-up visit to the outpatient service.

\section{Statistical analysis}

All data were imported and analyzed using the Statistical Package for Social Sciences software version 19.0
(IBM Corporation, Armonk, NY, USA). Normally distributed (continuous) variables are expressed as the mean \pm standard deviation, and independent $t$-tests were performed for the group comparisons. Nonparametric statistics were applied to data that were non-normally distributed, which are expressed as the median. Categorical variables are expressed as percentages and Pearson's Chi-squared tests were used to detect betweengroup independence. Stepwise logistic regression analysis (forward selection) was used to compare the high-dose quetiapine group ( $>300 \mathrm{mg} /$ day) and low-dose quetiapine group ( $\leq 300 \mathrm{mg} /$ day) as dependent variables, and individual factors which achieved statistical significance as independent variables (probability for stepwise entry $=0.05$ and removal $=0.10$ ). All statistical tests were two-tailed $(\alpha=0.05)$.

\section{Results}

\section{Patient population}

A search of the inpatient and outpatient medical records database identified 175 patients who met our inclusion criteria. There were 89 male and 86 female patients aged 16-62 (median 36) years. Their age at disease onset was 12-60 (median 25) years, with an illness duration of 0.1-37.9 (median 6.5) years. Educational achievement was as follows: 63 patients $(36.0 \%)$ had completed up to middle school; $52(29.7 \%)$ had completed high school, and 60 (34.3\%) were at or above college level. Fifty-five patients $(31.4 \%)$ had a family history of bipolar disorder across three generations. The most recent episodes were of manic or mixed type (127 patients, $72.6 \%$ ), depressive type (48 patients, $27.4 \%$ ), and accompanied by psychotic features (73 patients, $41.7 \%$ ). Following hospitalization, 175, 161, and 148 patients, respectively, returned to clinic for a follow-up visit at months 1,3 , and 6 . The remaining patients were lost to follow-up.

\section{Treatment and dosing}

In the acute treatment phase, $99.4 \%$ of patients $(174 / 175)$ received quetiapine combined with a mood stabilizer and/or antidepressant therapy. Only one patient received quetiapine as monotherapy. The mean dose of quetiapine during acute treatment was $395.7 \mathrm{mg} /$ day. Post-hospitalization follow-up data showed that all patients (171/171) were on adjunctive quetiapine therapy at month 1 at a mean dose of $375 \mathrm{mg} /$ day. At month 3, 90.7\% (146/161) were on quetiapine as adjunctive therapy and $1.2 \%(2 / 161)$ were on quetiapine monotherapy, at a mean dose of $330.6 \mathrm{mg} /$ day. At month 6 , $84.6 \%(125 / 148)$ were on quetiapine as adjunctive therapy and $1.4 \%$ (2/148) were on quetiapine monotherapy, at a mean dose of $293.7 \mathrm{mg} /$ day. 
One hundred and fifteen of the 175 patients (65.7\%) were taking lithium at a mean dose of $946.3 \mathrm{mg} / \mathrm{day}$ during the acute treatment period. Subsequently, $64.4 \%$ of patients (113/175) were receiving lithium at a mean dose of $913.3 \mathrm{mg}$ /day at month $1,61.5 \%(99 / 161)$ were receiving a mean dose of $898.5 \mathrm{mg} /$ day at month 3 , and $54.7 \%(81 / 148)$ were receiving a mean dose of $851.9 \mathrm{mg} /$ day at month 6 .

One hundred and twelve of the 175 patients $(64.0 \%)$ were receiving sodium valproate at a mean dose of $1054.9 \mathrm{mg} /$ day during acute treatment. During the maintenance period, $63.4 \%(111 / 175)$ were on sodium valproate at a mean dose of $1007.7 \mathrm{mg} /$ day at month $1,56.5 \%(91 / 161)$ were on $981.3 \mathrm{mg} /$ day at month 3 , and $54.1 \%(80 / 148)$ were on $951.8 \mathrm{mg} /$ day at month 6 . Corresponding data for patients receiving lamotrigine are not provided here because of the low number of patients involved (4/175).

Male patients received a significantly higher quetiapine dose than female patients during the acute treatment phase $(\mathrm{Z}=-3.931, P=0.000)$, and at month $1(\mathrm{Z}=-3.476$, $P=0.001)$ and month $3(\mathrm{Z}=-2.372, P=0.018)$.

The mean quetiapine dose was significantly higher for patients with a manic or mixed state than for those with depression during the acute treatment phase $(Z=-3.559$, $P=0.000)$, and at month $1(\mathrm{Z}=-3.228, P=0.001)$ and month $3(\mathrm{Z}=-2.803, P=0.005)$.

Patients with psychotic features also received a significantly higher dose of quetiapine than those who did not experience psychosis in the acute treatment phase $(\mathrm{Z}=-2.360, P=0.018)$, and at month $1(\mathrm{Z}=-2.658$, $P=0.008)$ and month $3(\mathrm{Z}=-2.328, P=0.020)$.

Finally, comparing the quetiapine dose according to patient age, younger patients ( $<50$ years) received a significantly higher quetiapine dose than did older patients
( $\geq 50$ years) during the acute treatment phase $(\mathrm{Z}=-2.386$, $P=0.017)$, and at month $1(\mathrm{Z}=-2.871, P=0.004)$ and month $3(\mathrm{Z}=-2.479, P=0.013)$. No statistically significant differences in quetiapine dose were found for any of the above-mentioned variables at month 6 (see Table 1).

\section{Clinical characteristics of groups receiving different quetiapine doses}

We assessed whether gender, type of episode, and presence of accompanying psychotic features influenced any of the differences identified for quetiapine dose. Taking quetiapine $\leq 300 \mathrm{mg} /$ day as the low-dose quetiapine group and $>300 \mathrm{mg} /$ day as the high-dose quetiapine group, we compared the clinical characteristics of patients in these two dose groups during the acute phase and during the maintenance phase, with assessments done again at months 1,3 , and 6 (see Table 2).

There were significantly more male patients in the high-dose quetiapine group than in the low-dose quetiapine group during acute treatment $\left(\chi^{2}=7.089, P=0.008\right)$, and at months $1\left(\chi^{2}=6.513, P=0.011\right), 3\left(\chi^{2}=8.763, P=0.003\right)$, and $6\left(\chi^{2}=7.219, P=0.007\right)$. The lithium dose was significantly higher in the high-dose quetiapine group than in the low-dose quetiapine group during acute treatment $(\mathrm{t}=-2.731$, $P=0.007)$, and at months $1(\mathrm{t}=-3.015, P=0.003)$, $3(\mathrm{t}=-3.454, P=0.001)$, and $6(\mathrm{t}=-2.626, P=0.010)$. The dose of sodium valproate was also significantly higher in the high-dose quetiapine group than in the low-dose quetiapine group during acute treatment $(\mathrm{t}=-2.692, P=0.008)$, and at months $1(\mathrm{t}=-3.329, P=0.001), 3(\mathrm{t}=-3.969, P=0.000)$, and $6(\mathrm{t}=-2.747, P=0.007)$.

Logistic regression analysis showed that male gender (odds ratio [OR] 2.712, 95\% confidence interval [CI]

Table I Mean quetiapine dose ( $\mathrm{mg} /$ day) according to clinical features

\begin{tabular}{|c|c|c|c|c|}
\hline & $\begin{array}{l}\text { Acute treatment } \\
(n=175)\end{array}$ & $\begin{array}{l}\text { Month I } \\
(n=\mid 7 I)\end{array}$ & $\begin{array}{l}\text { Month } 3 \\
(n=148)\end{array}$ & $\begin{array}{l}\text { Month } 6 \\
(n=127)\end{array}$ \\
\hline Male & $445.5 \pm 169.8$ & $419.2 \pm 163.5$ & $361.5 \pm 160.8$ & $318.3 \pm 145.0$ \\
\hline Female & $344.2 \pm 151.0$ & $330.3 \pm 152.1$ & $300.0 \pm 152.8$ & $271.6 \pm 163.5$ \\
\hline$P$ value & 0.000 & 0.001 & 0.018 & 0.060 \\
\hline Manic or mixed episode & $424.8 \pm 156.8$ & $400.6 \pm 156.2$ & $354.6 \pm 152.2$ & $311.1 \pm 151.5$ \\
\hline Depressive episode & $318.8 \pm 174.6$ & $307.5 \pm 165.2$ & $275.6 \pm 163.4$ & $251.4 \pm 161.3$ \\
\hline$P$ value & 0.000 & 0.001 & 0.005 & 0.074 \\
\hline With psychotic features & $430.8 \pm 165.8$ & $4 \mid 3.4 \pm 162.3$ & $371.3 \pm 174.4$ & $319.3 \pm 163.0$ \\
\hline Without psychotic features & $370.6 \pm 166.3$ & $347.8 \pm 159.8$ & $302.8 \pm 142.8$ & $275.3 \pm 149.6$ \\
\hline$P$ value & 0.018 & 0.008 & 0.020 & 0.154 \\
\hline Age $<50$ years & $408.9 \pm 167.8$ & $390.7 \pm 163.2$ & $344.8 \pm 158.1$ & $303.3 \pm 156.5$ \\
\hline Age $\geq 50$ years & $329.3 \pm 156.7$ & $294.6 \pm 142.9$ & $257.3 \pm 148.4$ & $245.2 \pm 149.1$ \\
\hline$P$ value & 0.017 & 0.004 & 0.013 & 0.120 \\
\hline
\end{tabular}




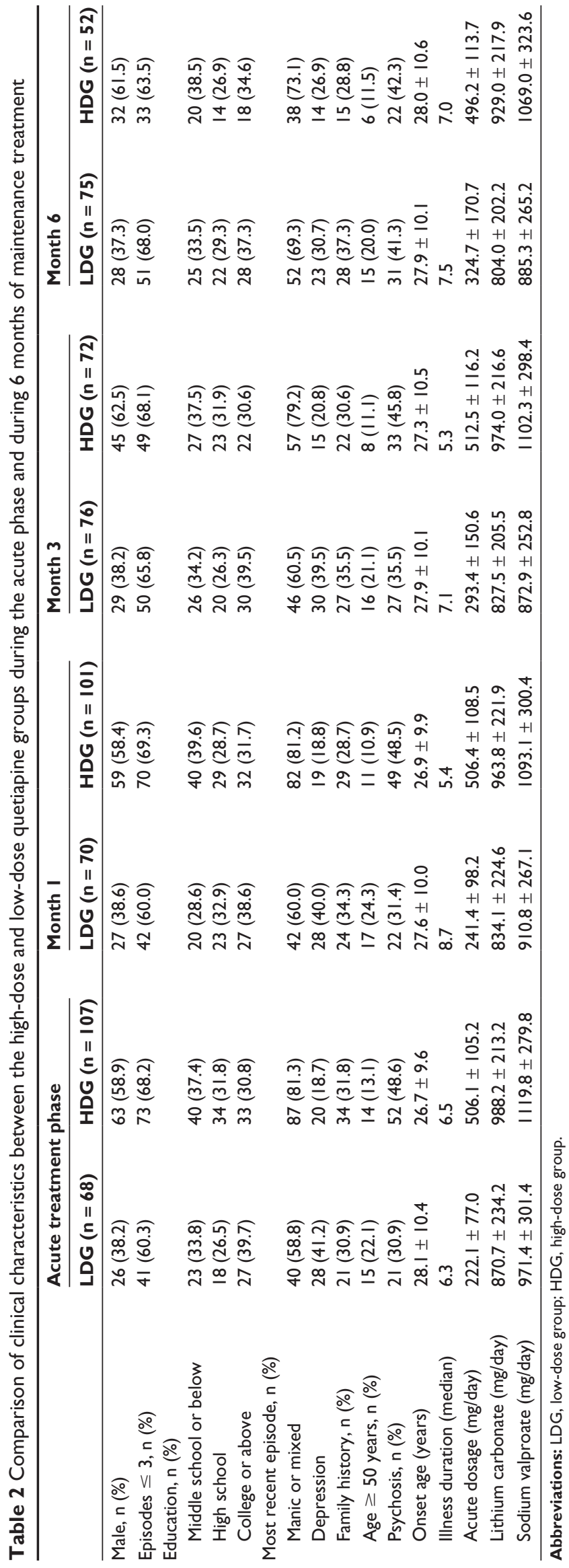

1.372-5.362, $P<0.01$ ), a manic or mixed episode (OR $2.786,95 \%$ CI $1.362-5.699, P<0.01$ ), and accompanying psychotic features (OR 2.658, 95\% CI 1.318-5.361, $P<0.01)$ were independently associated with high-dose quetiapine treatment during the acute phase (Table 3). Male gender (OR 2.761, 95\% CI 1.379-5.531, $P<0.01$ ), a manic or mixed episode (OR 2.626, 95\% CI 1.258-5.482, $P<0.01$ ), accompanying psychotic features (OR 2.473, 95\% CI 1.222-5.005, $P<0.01$ ), and age $<50$ years (OR $2.834,95 \%$ CI 1.148-6.997, $P<0.01$ ) were independently associated with high-dose quetiapine at month 1 . Male gender (OR 2.583, 95\% CI 1.313-5.080, $P<0.01$ ) and a manic or mixed episode (OR 2.334, 95\% CI 1.102-4.945, $P<0.01$ ) were independently associated with high-dose quetiapine at month 3. Only male gender (OR 2.686, 95\% CI 1.296-5.566, $P<0.01)$ was independently associated with high-dose quetiapine at month 6 .

\section{Discussion}

It is important that psychiatric clinicians are familiar with the dose and timing of maintenance quetiapine therapy in patients with bipolar disorder who have received adjunctive therapy combining quetiapine with mood stabilizers during the acute phase and who remain clinically stable during the maintenance phase, in order to optimize the risk-benefit ratio of antipsychotic medication as maintenance therapy. In the present study, we evaluated clinical data from patients who were diagnosed with bipolar disorder according to ICD-10 criteria and were admitted to hospital. These patients received quetiapine as adjunctive therapy during their hospitalization and continued it on the outpatient service after discharge from hospital. Therefore, our data can be considered objective and reliable, and as reflecting medication use in a naturalistic setting. This study provides valuable information regarding current treatment of bipolar disorder in the acute and maintenance settings, and identifies some clinical factors associated with dosing of quetiapine.

Quetiapine can be used as monotherapy to treat bipolar disorder because of its mood-stabilizing properties. ${ }^{9}$ However, this study indicates that the most common strategy at present involves use of quetiapine as adjunctive therapy in combination with mood stabilizers in both the acute and maintenance treatment of this illness.

Psychiatric clinicians need to address the issue of the optimal dose of quetiapine. In the United States, the recommended quetiapine dose range is $300-600 \mathrm{mg}$ /day for acute treatment of bipolar depression and 400-800 mg/day for acute treatment of bipolar mania. Further, it is recommended 
Table 3 Logistic regression analysis of the factors associated with quetiapine dosage

\begin{tabular}{|c|c|c|c|c|c|c|}
\hline & $\begin{array}{l}\text { Regression } \\
\text { coefficient } \beta\end{array}$ & $\begin{array}{l}\text { Standard } \\
\text { error }\end{array}$ & Wald $\chi^{2}$ & $P$ & OR & $95 \% \mathrm{Cl}$ \\
\hline \multicolumn{7}{|l|}{ Acute treatment phase } \\
\hline Male & 0.998 & 0.348 & 8.232 & 0.004 & 2.712 & $1.372-5.362$ \\
\hline Manic or mixed episode & 1.025 & 0.365 & 7.870 & 0.005 & 2.786 & $1.362-5.699$ \\
\hline With psychotic features & 0.978 & 0.358 & 7.462 & 0.006 & 2.658 & $|.3| 8-5.36 \mid$ \\
\hline \multicolumn{7}{|l|}{ Month I } \\
\hline Male & 1.016 & 0.354 & 8.213 & 0.004 & 2.761 & $\mid .379-5.53 \mathrm{I}$ \\
\hline Manic or mixed episode & 0.965 & 0.376 & 6.608 & 0.010 & 2.626 & $1.258-5.482$ \\
\hline With psychotic features & 0.906 & 0.360 & 6.339 & 0.012 & 2.473 & $1.222-5.005$ \\
\hline Age $<50$ years & 1.042 & 0.461 & 5.101 & 0.024 & 2.834 & $1.148-6.997$ \\
\hline \multicolumn{7}{|l|}{ Month 3} \\
\hline Male & 0.949 & 0.345 & 7.561 & 0.006 & 2.583 & $1.313-5.080$ \\
\hline Manic or mixed episode & 0.848 & 0.383 & 4.899 & 0.027 & 2.334 & $1.102-4.945$ \\
\hline \multicolumn{7}{|l|}{ Month 6} \\
\hline Male & 0.988 & 0.372 & 7.060 & 0.008 & 2.686 & $1.296-5.566$ \\
\hline
\end{tabular}

Abbreviations: $\mathrm{Cl}$, confidence interval; OR odds ratio.

that quetiapine should continue to be given at a dose necessary to maintain clinical stability. ${ }^{10}$ Our current study identified a mean quetiapine dose of $424.8 \pm 156.8 \mathrm{mg} /$ day for the acute treatment of bipolar mania or a mixed episode, and $318.8 \pm 174.6 \mathrm{mg} /$ day for acute treatment of bipolar depression, which is consistent with the recommended doses.

Our study suggests that a higher dose of quetiapine may be needed for acute treatment of male patients, those aged older than 50 years, and those experiencing a manic or mixed episode or having accompanying psychotic features, which is consistent with our clinical experience. Patients whose bipolar disorder remained clinically stable during the first 6 months of the maintenance period were usually prescribed a decreased dose of quetiapine, which is in line with the observations of Ketter et al ${ }^{10}$ and of Goldberg et al. ${ }^{11}$ Male patients who remained clinically stable during this time usually continued their higher doses of quetiapine (>300 mg/day). The most recent type of bipolar episode (manic or mixed, depression) should be taken into consideration when deciding on the quetiapine dose for at least the first 3 months of the maintenance phase. Whether or not patients have accompanying psychosis seems to be less relevant to the quetiapine dose prescribed as maintenance therapy. In our study, the influence of accompanying psychosis was only observed in the first month of the maintenance phase, which might have been because of the generally short duration of psychosis in bipolar patients. In addition to the above-mentioned factors, patient age should be taken into account when deciding on the maintenance dose of quetiapine. Lower doses should be given to patients who are older than 50 years.
This retrospective cohort study was conducted in one center, so only includes patients registered in the single database of one hospital, so the possibility of selection bias cannot be excluded. Future prospective studies including a larger sample size will probably yield more robust results.

In conclusion, this study suggests that higher doses of quetiapine $(>300 \mathrm{mg} /$ day) are prescribed more often for bipolar patients who are male, those who have manic or mixed episodes, and those who have psychotic features during the acute phase of the illness. For patients who are clinically stable during the subsequent 6-month maintenance phase, the dose of quetiapine should be adjusted according to gender and the most recent episode type.

\section{Disclosure}

The authors report no conflicts of interest in this work.

\section{References}

1. Altamura AC, Madaro D, Salvadori D. Quetiapine in acute mania: a case report (with 6 month follow-up). Int J Psychiatry Clin Pract. 2001;5(4):283-285.

2. Bowden CL, Grunze H, Mullen J, et al. A randomized, double-blind, placebo-controlled efficacy and safety study of quetiapine or lithium as monotherapy for mania in bipolar disorder. J Clin Psychiatry. 2005;66(1):111-121.

3. McIntyre RS, Brecher M, Paulsson B, et al. Quetiapine or haloperidol as monotherapy for bipolar mania 12-week, double-blind, randomised, parallel-group, placebo-controlled trial. Eur Neuropsychopharmacol. 2005;15(5):573-585.

4. Sachs G, Chengappa KN, Suppes T, et al. Quetiapine with lithium or divalproex for the treatment of bipolar mania: a randomized, double-blind, placebo-controlled study. Bipolar Disord. 2004;6(3): 213-223.

5. Calabrese JR, Keck PE, MacFadden W, et al. A randomized, doubleblind, placebo-controlled trial of quetiapine in the treatment of bipolar I or II depression. Am J Psychiatry. 2005;162(7):1351-1360. 
6. Altamura AC, Bassetti R, Fumagalli S. Pharmacotherapy of mixed anxiety/depression disorders. In: Kasper S, Den Boer JA, Sitsen JM, editors. Handbook of Depression and Anxiety. New York, NY: Marcel Dekker Inc; 2003.

7. Altamura AC, Salvadori D, Madaro D, et al. Efficacy and tolerability of quetiapine in the treatment of bipolar disorder: preliminary evidence from a 12-month open-label study. J Affect Disord. 2003;76(1-3):267-271.

8. Mundo E, Cattaneo E, Zanoni S, et al. The use of atypical antipsychotics beyond psychoses: efficacy of quetiapine in bipolar disorder. Neuropsychiatr Dis Treat. 2006;2(2):139-148.
9. Altamura AC, Mundo E, Dell'Osso B, et al. Quetiapine and classical mood stabilizers in the long-term treatment of bipolar disorder: a 4-year follow-up naturalistic study. J Affect Disord. 2008;110(1-2): $135-141$.

10. Ketter TA, Brooks JO 3rd, Hoblyn JC, et al. Long-term effectiveness of quetiapine in bipolar disorder in a clinical setting. J Psychiatr Res. 2010;44(14):921-929.

11. Goldberg JF, Kelley ME, Rosenquist KJ, et al. Effectiveness of quetiapine in rapid cycling bipolar disorder: a preliminary study. $J$ Affect Disord. 2007;105(1-3):305-310.

\section{Publish your work in this journal}

Neuropsychiatric Disease and Treatment is an international, peerreviewed journal of clinical therapeutics and pharmacology focusing on concise rapid reporting of clinical or pre-clinical studies on a range of neuropsychiatric and neurological disorders. This journal is indexed on PubMed Central, the 'PsycINFO' database and CAS.
The manuscript management system is completely online and includes a very quick and fair peer-review system, which is all easy to use. Visit http://www.dovepress.com/testimonials.php to read real quotes from published authors.

Submit your manuscript here: http://www.dovepress.com/neuropsychiatric-disease-and-treatment-journal 